\title{
klymenko 0. THE CONCEPT FOR AN IMPLEMENTATION OF STATE POLICY IN THE FIELD OF LABELING AND REGULATION OF ESSENTIAL ENVIRONMENTAL PROPERTIES OF WHEELED VEHICLES
}

The object of research is the field of labeling and regulation of environmental properties of road vehicles. The research method is based on a conceptual basis for the structure of environmental labeling data of road vehicles required to ensure ecological marketing and access control to infrastructure. Several principles of effective state policy in the field of labeling and regulation of essential environmental properties of wheeled vehicles are proposed to ensure:

- reduction of emissions of toxic substances by road transport in operation and improvement of air quality in cities;

- decrease in other manifestations of man-caused pressure of road transport on the environment and people;

- in general, improving the living conditions of people in cities;

- reduction of energy consumption and greenhouse gas emissions by transport.

Terms and definitions are formulated in the part:

- current level of ecological danger of ingredient pollution, indicators of energy-efficiency and ecological marking, essential environmental properties of a wheeled vehicle in operation, and at other stages of the life cycle;

- definitions of an environmentally friendly and energy-efficient wheeled vehicle; ecological zones of regulated use of road and other infrastructure;

- single national database of the life cycle of wheeled vehicles.

The principles of state regulation in the field of essential ecological properties and ecologically favourable use of wheeled vehicles are offered, covering:

- establishment of progressive ecological requirements;

- identification and labeling of fundamental environmental properties of wheeled vehicles and bringing them to consumers;

- introduction of a progressive taxation system and the «polluter pays» principle, targeted use of resources;

- differentiation of access to the transportation market;

- introduction of advanced technologies and measures for periodic and selective control of serviceability, stimulation of economic and rational use of fuel and energy resources.

The vital conceptual provisions of the system of labeling of essential environmental properties and introduction of ecological zones of regulated use of road and other infrastructure are defined.

Keywords: road vehicles, essential environmental properties, eco-labeling, ecological zones, state regulation.

Received date: 30.04 .2020

Accepted date: 11.06 .2020

Published date: 31.10 .2020
Copyright (C) 2020, Klymenko O.

This is an open access article under the CC BY license (http://creativecommons.org/licenses/by/4.0)

\section{Introduction}

Road transport is the dominant environmental pollutant in crowded areas. Dangerous concentrations of toxic substances in the air caused by road transport, and other types of man-made pressure on the environment and humans, cause significant and irreparable harm to public health.

Air pollution according to confirmed data alone kills about 3 million people annually in the world [1].

The solution to this problem requires the introduction of an agreed set of measures, among which special attention is paid to the introduction of environmental labeling and regulation of the essential environmental properties of wheeled vehicles [2-4].
Labeling and regulation of significant environmental properties of wheeled vehicles during admission to the market and during operation, in particular, with the introduction of environmental zones with differentiated conditions for access to infrastructure, is rapidly spreading across the European continent [3,5]. The member states of the European Union are introducing different, largely incompatible approaches [6, 7] to eco-labeling of cars and the introduction of ecological zones in cities, based on the fundamental possibilities of state regulation in this area, specific conditions and numerous national characteristics. The effectiveness of these approaches also varies widely [8, 9].

Other countries around the world have already introduced, or are in the process of introducing [10] various options for vehicle eco-labeling systems. 
This requires the development and implementation of unified approaches and tools in this area [11], taking into account the heterogeneous international experience.

The object of research is the field of labeling and regulation of the ecological properties of wheeled vehicles.

The aim of research is to develop a concept, to determine the basic principles of an effective state policy in the field of labeling and regulation of the essential environmental properties of wheeled vehicles to ensure:

- reduction of emissions of toxic substances by road transport in operation and improvement of the quality of atmospheric air in cities;

- reduction of other manifestations of man-made pressure of road transport on the environment and humans;

- in general, improvement of living conditions for people in cities;

- reduction of the consumption of energy resources

by transport;

- reduction of greenhouse gas emissions from transport.

\section{Methods of research}

The results of a conceptual study are presented. The research used the following scientific methods:

- method of systems analysis in the preliminary study of world experience in the introduction of marking and regulation of the essential environmental properties of wheeled vehicles;

- analysis of positive and negative experiences directly on the ground, relevant determinants and driving factors, as well as other related issues in a particular area; - method of classification, in particular when establishing the essential ecological properties of wheeled vehicles; - method of synthesis in the development of proposals for policy in a particular area, taking into account the author's experience in the development of draft legal acts on technical regulation in the areas of standardization of energy efficiency indicators and specific emissions of pollutants by road transport;

- conceptual framework for the data structure of vehicle eco-labels needed to support technical regulation, environmental marketing and the management of vehicle access to infrastructure.

Proposals to introduce the level of environmental hazard of vehicles by the level of ingredient pollution, their respective differentiation and the establishment of ecological zones are based on the results of studies published by the author in [12, 13].

\section{Research results and discussion}

This Concept uses the following basic concepts:

1) the current level of hazard of ingredient pollution (abbreviated as EHL) of a wheeled vehicle - a conditional average level of the main negative impact on the environment during the operation of a wheeled vehicle. It is assumed that EHL is caused by emissions of the main pollutants into the atmospheric air, constructed as an aggregate indicator of carbon monoxide, taking into account their relative toxicity. EHL also takes into account the age of the vehicle and the corresponding degradation of its ecological properties;

2) indicators of the efficiency of energy use by wheeled vehicles - a system of indicators that collectively characterize the efficiency of energy use by wheeled vehicles in various operating conditions. They are the basis for vehicle comparison, appropriate consumer information and informed vehicle selection. They are also the basis for the introduction of measures to stimulate the acquisition and use of the most energy efficient vehicle designs in accordance with the preferential conditions of their operation;

3 ) emissions of carbon dioxide from a wheeled vehicle - average emissions under typical operating conditions, characterizing the structure of the vehicle as a whole or its heat engine;

4) environmental labeling (abbreviated as eco-labeling) of wheeled vehicles - a system of measures to inform about the essential environmental properties of a wheeled vehicle. It is the basis for regulating the access of vehicles to the market and to the infrastructure, determination of tax rates, the cost of using road infrastructure, including in ecological zones. At the same time, special labels and other means of marking, electronic chips, electronic databases and other means of determining, creating, storing, transmitting, displaying and using information are used;

5) essential ecological properties of a wheeled vehicle in operation include:

- current hazard level of ingredient contamination;

- type of motor fuel or other source of energy;

- type of power plant;

- indicators of energy efficiency;

- averaged specific emissions of carbon dioxide;

- level of acoustic noise (sound pressure) when the vehicle is moving;

- factors of intensity of road surface wear and formation of wear products of pneumatic tires and road surface. Should take into account the gross design mass of the vehicle, the maximum load on one axle, the wheel formula taking into account the steering wheels, and other essential design parameters. Separately, the use of studded tires must be considered and regulated;

6) environmentally friendly wheeled vehicle a vehicle, the level of danger of ingredient pollution in operation corresponds to a certain minimum technically achievable and economically acceptable value in comparison with other vehicles. At the same time, vehicles on the market are considered in accordance with the current level of development of science, technology and technology. Also, this is considered a vehicle that meets the most stringent international standards (technical regulations) in force at the time of assessment for emissions of toxic pollutants, taking into account the type of energy carrier (fuel) that is used;

7) energy efficient wheeled vehicles - a vehicle which energy efficiency indicators in operation meet, in aggregate, a certain technically achievable and economically acceptable value in comparison with other vehicles. At the same time, vehicles presented on the market are considered in accordance with the current level of development of science and technology. Also, this is considered a vehicle that meets the most stringent international standards (technical regulations) in force at the time of assessment for energy efficiency or specific emissions of carbon dioxide. This takes into account the type of energy carrier (fuel) that is used;

8) ecological zones - zones of regulated use of road and other infrastructure, the designations of which and other means of access control and payment for use are coordinated with the eco-labeling system of wheeled vehicles and differentiated in accordance with their essential ecological properties; 
9) the «polluter pays» principle - the principle according to which the costs of society related to measures to prevent, control and reduce pollution are covered by the polluter;

10) until the essential environmental properties of a wheeled vehicle at the stages of its production and disposal, the data on:

- total energy costs and volumes of greenhouse gas emissions, volumes of emissions of toxic substances generated during the production and subsequent disposal of the vehicle, its replacement parts and operating materials; - availability of available technologies and the degree of recovery of materials of construction;

- danger of waste generated during the disposal of the vehicle and the availability of available technologies for the safe handling and disposal of such waste;

11) unified national database of the life cycle of wheeled vehicles - a database containing information specified by law regarding the life cycle of wheeled vehicles. The base should include vehicles registered in the country and those in service in the country. Should contain data, in particular, in the part:

- available data on their production, significant design features;

- conformity assessment;

- first access to operation;

- period of operation and significant events associated with this;

- periodic verification of serviceability;

- significant ecological properties;

- changes in design (re-equipment);

- maintenance and repair, restoration, replacement of structural elements subject to periodic replacement;

- further disposal, withdrawal from circulation and reuse of materials of construction and components of the vehicle.

State regulation in the field of essential environmental properties and environmentally friendly use of wheeled vehicles is carried out by, in particular:

1) establishment of mandatory and progressive environmental requirements (norms), in particular, those determined by international technical regulations, in wheeled vehicles first enter the market;

2) determination and labeling of the current level of environmental hazard, indicators of energy efficiency, specific emissions of carbon dioxide, and other significant environmental properties of wheeled vehicles;

3) bringing to consumers the level of environmental hazard, indicators of energy efficiency, specific emissions of carbon dioxide, and other significant environmental properties of wheeled vehicles offered on the market. Thus, consumer acceptance of a familiar and informed choice in favor of environmentally friendly and energy efficient designs for wheeled vehicles, taking into account the adopted and prospective fiscal and other incentive measures. In particular, taking into account the advantages in the use of infrastructure facilities by such vehicles, including the advantages in terms of access to ecological zones, parking spaces and other facilities;

4) establishment of a progressive taxation system for the acquisition of wheeled vehicles, will stimulate an accelerated and economically expedient renewal of the fleet to environmentally friendly and energy-efficient designs of wheeled vehicles, based on their significant environmental properties;
5) introduction of the «polluter pays» principle, though, in particular, the introduction of ecological zones of regulated access and payment for the use of road and other infrastructure, differentiated depending on the essential ecological properties of wheeled vehicles;

6) targeted use of the collected financial resources. This refers to the payment of access to ecological zones and other infrastructure, fines for violation of the established requirements for eco-labeling and the conditions of access to road and other infrastructure. Resources should be directed exclusively to financing activities for:

- prevention, control and reduction of environmental pollution by wheeled vehicles;

- reduction of consumption of fuel and energy resources by transport;

- development of environmentally friendly, safe, convenient and comfortable public transport as an attractive alternative for citizens to use private transport;

- development and maintenance of the road infrastructure in a satisfactory condition;

- other activities aimed at sustainable development of road transport;

7) use of the level of environmental hazard and other certain significant environmental properties of wheeled vehicles, as advantages in tenders for the supply of vehicles and tenders for transportation. At the same time, the conditions of transportation and the corresponding significance (or weight) of individual environmental properties of vehicles must be taken into account;

8) implementation of maintaining the environmental properties of the vehicle laid down by the manufacturer during the entire period of its operation;

9) implementation of progressive, in accordance with the development of technology, technology and measures:

a) periodic monitoring of the suitability of wheeled vehicles for operation with the determination of the operability of the main structural elements responsible for the level of emissions of pollutants into the atmospheric air and the level of acoustic noise (sound pressure);

b) selective roadside instrumental control of the level of pollutant emissions and the level of acoustic noise;

10) stimulating the economical and rational use of fuel and energy resources by wheeled vehicles in operation by business entities, organizations and institutions;

11) establishment of liability for violation of certain rules for eco-labeling wheeled vehicles, their admission to infrastructure facilities and payment for the use of infrastructure facilities, and the use of vehicles that are inappropriate to the established requirements for serviceability;

12) establishment of a progressive system of taxation of fuel and energy resources using wheeled vehicles. This will stimulate the reduction of atmospheric air pollution by consciously choosing by consumers in favor of vehicles using more environmentally friendly types of energy, taking into account the available technologies for their use on board the vehicle. It will also contribute to the optimization (balancing) of the structure of consumption of various types of energy resources in general by the fleet of wheeled vehicles.

The regulation should cover road vehicles with heading codes $870120,8702,8703,8704,8705,8711$ according to the Commodity codes of the harmonized tariff schedule. Should apply to both produced in the country and imported into the customs territory of the country, new and used vehicles. The sale and first registration of the above 
vehicles must be carried out subject to the determination and marking of essential environmental properties in the process of useful use (operation):

- current level of environmental hazard of ingredient pollution;

- type of motor fuel or other source of energy;

- type of power plant;

- indicators of energy efficiency;

- averaged specific emissions of carbon dioxide;

- level of acoustic noise (sound pressure) when the vehicle is moving;

- factors of intensity of road surface wear and formation of wear products of pneumatic tires and road surface.

And also subject to the determination by the method of declaration and labeling of the essential environmental properties of a wheeled vehicle at the stages of its production and disposal. The consumer at the points of sale of vehicles, based on the approaches defined by the international standards of the ISO 14000 series, is provided with at least the following data:

- total energy costs and volumes of greenhouse gas emissions, volumes of emissions of the main types of toxic substances generated during the production and subsequent disposal of the vehicle, its replacement parts and operating materials;

- availability of available technologies and the degree of recovery of materials of construction;

- danger of waste generated during the disposal of the vehicle and the availability of available technologies for the safe handling and disposal of such waste.

The environmental labeling of wheeled vehicles at the points of sale and advertising should also contain other comprehensive information for the consumer for an informed choice in terms of at least:

- average cost of operating a vehicle for a certain period and mileage, and the total aggregate average cost of owning a vehicle, taking into account the projected cost of energy resources and other operating materials; - potential, legally defined or existing restrictions or preferences regarding the rights and conditions of access to transport infrastructure, in particular, access to ecological zones, which can be established by local administrations in accordance with a certain procedure and unified rules;

- impact of a vehicle on climate change by assessing the average total greenhouse gas emissions throughout all stages of its life cycle.

The marking of wheeled vehicles in operation is carried out, in particular, during a periodic check of the suitability for use or undergoing maintenance, the repair of a wheeled vehicle, without fail, for such essential environmental properties:

- current level of environmental hazard of ingredient pollution;

- type of motor fuel or other source of energy;

- type of power plant;

- level of acoustic noise (sound pressure) when the vehicle is moving;

- factors of intensity of road surface wear and formation of wear products of pneumatic tires and road surface.

The marking of the current level of environmental hazard of transit or temporarily imported wheeled vehicles with foreign registration is carried out without fail according to a simplified and accelerated procedure using default data. If necessary, their owners, if there is an appropriate evidence base, can voluntarily obtain accurate data on the essential environmental properties and appropriate labeling of such vehicles. This should allow obtaining legally defined preferences for access and cost of using transport infrastructure, if they meet the established requirements.

Differentiation and designation of ecological zones is carried out according to a unified system coordinated with the only system in the country for marking the essential ecological properties of wheeled vehicles.

The labeling of vehicles according to the hazard level of ingredient pollution, as the main negative factor of influence, is carried out according to the unified international system, as suggested in $[12,13]$.

It is assumed 5 levels of ecological zones, depending on the level of requirements for ingredient pollution, are established by local executive authorities within certain limits, as described in [13].

This allows local executive authorities to flexibly set the levels of access requirements and restrictions in different territories, taking into account various factors, including economic and social aspects.

Ecological zones with different requirements can be simultaneously established within a settlement. For example, in downtown areas, in pedestrian and tourist areas, or in certain areas with particularly difficult pollution situations, more stringent requirements may be set, taking into account public consensus. Also, the requirements for the maximum permissible levels of acoustic noise of vehicles can be established in a differentiated manner.

The designation of the type of power plant and the type of motor fuel or other source of energy used by the vehicle provides the possibility of establishing additional requirements and restrictions. For example, in the long term - direct restrictions on cars with diesel engines in places with a particularly unfavorable environmental situation, or the right of access only to electric vehicles in special zones defined by local communities.

The conditions for access to ecological zones, their boundaries and specific requirements are determined directly by local executive authorities in accordance with uniform rules determined by the government of the country.

Conditions may include:

- collection of fees for the use of road infrastructure differentiated from the essential ecological properties of the vehicle;

- introduction of a ban on operation in certain areas of vehicles exceeding the established maximum permissible levels of hazard of ingredient pollution, including taking into account the type of motor fuel and the type of power plant;

- introduction of a ban on operation in certain areas of vehicles that create an acoustic noise level in excess of the established limits;

- introduction of a ban on operation in certain zones and in certain weather conditions of vehicles with an excessive level of wear and tear on the road surface (in particular, vehicles equipped with studded tires).

Uniform rates of payment and fines in the country should be introduced for violation of the established rules for eco-labeling vehicles and the conditions for their access to road infrastructure, depending on the significant environmental properties of the vehicle, the density of population concentration in the place of its operation, and other significant factors. 
The conditions for access to ecological zones can be set in time as:

- permanent;

- with a clearly defined frequency, as time dependences on the time of day, week, season of the year, with certain exceptions;

- adaptive, based on forecasts of deterioration of the atmospheric air, taking into account meteorological conditions, as a precautionary measure.

The terms of use of payment for the use of transport infrastructure can be based on various sets of environmental properties of the vehicle, with the definition of priorities in accordance with the need to solve the most pressing local problems:

- in different places and ecological zones;

- depending on the current level of ingredient and parametric pollution;

- depending on the state of the road network;

- depending on building density, population concentration and other factors.

For example, in dense residential areas, the emphasis may be placed on stringent requirements, primarily to the level of environmental hazard of ingredient pollution and acoustic noise from vehicles. Payment for the use of critical transport infrastructure, located at significant distances from settlements, may be based primarily on the factors of the intensity of road surface wear by the car, which, accordingly, will have priority.

Eco-labeling also contains a system of unified designations for the purpose of wheeled vehicles, to establish uniform exceptions in the country for, in particular, ambulances, police vehicles, and equipment of other emergency response services. It will also allow local executive authorities to establish local specific rules and exceptions to them, taking into account social aspects, and on the basis of public consensus.

\section{Conclusions}

A concept for the implementation of state policy in the field of labeling and regulation of the essential environmental properties of wheeled vehicles is proposed, assumes a systematic approach to ensuring environmental marketing and managing differentiated access of vehicles to the infrastructure. The concept is aimed at solving problems:

- reduction of emissions of toxic substances by road transport in operation and improvement of the quality of atmospheric air in cities;

- reduction of other manifestations of man-made pressure of road transport on the environment and humans;

- in general, improvement of living conditions for people in cities;

- reduction of the consumption of energy resources

by transport;

- reduction of greenhouse gas emissions from transport.

Terms and definitions in this area have been formulated. The key conceptual provisions of the system of marking the essential ecological properties of vehicles and the introduction of ecological zones in cities have been determined.

\section{References}

1. Ambient air pollution: A global assessment of exposure and burden of disease (2016). World Health Organisation. Available at: https://www.who.int/phe/publications/air-pollution-globalassessment/en/

2. Ricci, A., Gaggi, S., Enei, R., Tomassini, M., Fioretto, M., Gargani, F. et. al. (2017). Study on urban vehicle access regulations. European Commission, Directorate-General for Mobility and Transport. Available at: https://ec.europa.eu/transport/sites/ transport/files/uvar_final_report_august_28.pdf

3. Feasibility Study: European City Pass for Low Emission Zones, Annex A: Standards and Guidance Document (2014). ECORYS Available at: https://urbanaccessregulations.eu/images/Reports/ EU draft guidance LEZ Final Report Standards and Guidance_submitted.pdf

4. Hill, N., Windisch, E., Klimenko, A. (2016). Development of national policy on regulation of road transport $\mathrm{CO}_{2}$ emissions and energy consumption in Ukraine. Ricardo Energy \& Environment, State Enterprise State Road Transport Research Institute, 212. Available at: https://europa.eu/capacity4dev/climaeastpolicyproject/documents/development-national-policy-regulation-roadtransport-co2-emissions-and-energy-consumption

5. Amundsen, A. H., Sundvor, I. (2018). Low Emission Zones in Europe Requirements, enforcement and air quality. ТØI report 1666/2018. Available at: http://www.toi.no/getfile.php?mmfileid=49204

6. Yang, Z., Zhu, L., Bandivadekar, A. (2015). A Review and Evaluation of Vehicle Fuel Efficiency Labeling and Consumer Information Programs. Asia-Pacific Economic Cooperation. Energy Working Group. Available at: https://theicct.org/sites/default/files/publications/VFEL\%20paper\%20ICCT_\%20for\%20 APEC $\% 20-\% 2012 \% 20$ Nov\%202015\%20FINAL.pdf

7. Haq, G., Weiss, M. (2016). CO2 labeling of passenger cars in Europe: Status, challenges, and future prospects. Energy Policy, 95, 324-335. doi: http://doi.org/10.1016/j.enpol.2016.04.043

8. Holman, C., Harrison, R., Querol, X. (2015). Review of the efficacy of low emission zones to improve urban air quality in European cities. Atmospheric Environment, 111, 161-169. doi: http://doi.org/10.1016/j.atmosenv.2015.04.009

9. Bernard, Y., Miller, J., Wappelhorst, S., Braun, C. (2020). Impacts of the Paris low-emission zone and implications for other cities. FIA Foundation. Available at: https://theicct.org/sites/default/ files/publications/Paris-LEV-implications-03.12.2020.pdf

10. Donchenko, V. V., Kunin, Iu. I., Vaisblium, M. E., Gusarov, A. P., Semenikhin, A. N., Sazonova, G. M. (2016). Perspektivy vnedreniia o Rossiiskoi Federatsii sistemy «Eko-markirovki» vnov registriruemykh $i$ ekspluatiruemykh avtotransportnykh sredsto». Proekt PROON/GEF-Mintrans Rossii 00080462 «Sokraschenie vybrosov parnikovykh gazov ot avtomobilnogo transporta v gorodakh Rossii». Moscow, 230. Available at: https://alatransit.kz/sites/default/files/perspektivy_vnedreniya_v_rossiyskoy federacii sistemy eko - markirovki.pdf

11. Roadmap to a Single European Transport Area - Towards a competitive and resource efficient transport system (2011). European Commission. Available at: https://eur-lex.europa.eu/legal-content/ $\mathrm{EN} / \mathrm{TXT} / \mathrm{PDF} /$ ?uri=CELEX:52011DC0144\&from=EN

12. Klymenko, O. (2020). Results of research of the reduced emissions of pollutants by road vehicles of various environmental classes «Euro» as the basis of environmental hazard labeling. Eastern-European Journal of Enterprise Technologies, 1 (10 (103)), 43-52. doi: http://doi.org/10.15587/1729-4061.2020.196985

13. Klimenko, O., Sotsky, V., Shchelkunov, A., Kyrychenko, R., Ageev, V., Ustymenko, V., Gutarevych, Y. (2020). About the implementation of the national system of labeling of road vehicles regarding level of environmental hazard. Avtoshliakhovyk Ukrayiny, 1 (261), 2-13. doi: http://doi.org/10.33868/0365-8392-2020-1-261-2-13

Klymenko Oleksiy, PhD, Associate Professor, Research Laboratory of Fuels and Environment, Testing Center of Wheeled Vehicles for Scientific and Technical Development, State Entreprise «State Road Transport Research Institute», Kyiv, Ukraine, ORCID: http://orcid.org/ 0000-0002-2323-6839, e-mail: aklimenko.insat@gmail.com 